\title{
Microbial Removal Using Layered Double Hydroxides and Iron (Hydr)oxides Immobilized on Granular Media
}

\author{
Jeong-Ann Park, Chang-Gu Lee, Seong-Jik Park, Jae-Hyeon Kim, Song-Bae Kim ${ }^{\dagger}$ \\ Environmental Biocolloid Engineering Laboratory, Department of Rural Systems Engineering, Seoul National University, Seoul 151-921, Korea
}

\begin{abstract}
The objective of this study was to investigate microbial removal using layered double hydroxides (LDHs) and iron (hydr)oxides (IHs) immobilized onto granular media. Column experiments were performed using calcium alginate beads (CA beads), LDHs entrapped in CA beads (LDH beads), quartz sand (QS), iron hydroxide-coated sand (IHCS) and hematite-coated sand (HCS). Microbial breakthrough curves were obtained by monitoring the effluent, with the percentage of microbial removal and collector efficiency then quantified from these curves. The results showed that the LDH beads were ineffective for the removal of the negatively-charged microbes (27.7\% at $1 \mathrm{mM}$ solution), even though the positively-charged LDHs were contained on the beads. The above could be related to the immobilization method, where LDH powders were immobilized inside CA beads with nano-sized pores (about $10 \mathrm{~nm}$ ); therefore, micro-sized microbes $(E$. coli $=1.21 \mu \mathrm{m}$ ) could not diffuse through the pores to come into contact with the LDHs in the beads, but adhere only to the exterior surface of the beads via polymeric interaction. IHCS was the most effective in the microbial removal (86.0\% at $1 \mathrm{mM}$ solution), which could be attributed to the iron hydroxide coated onto the exterior surface of QS had a positive surface charge and, therefore, effectively attracted the negatively-charged microbes via electrostatic interactions. Meanwhile, HCS was far less effective (35.6\% at 1 mM solution) than IHCS because the hematite coated onto the external surface of QS is a crystallized iron oxide with a negative surface charge. This study has helped to improve our knowledge on the potential application of functional granular media for microbial removal.
\end{abstract}

Keywords: Microbial removal, Layered double hydroxides, Iron (hydr)oxides, Calcium alginate bead, Iron hydr(oxide)-coated sand

\section{Introduction}

Contamination of surface water and groundwater by microbial pathogens is a serious environmental problem, causing deterioration of the quality of drinking water resources and posing a great threat to human health. Inadequate sanitation causes waterborne diseases, leading to a great number of deaths around the world [1]. Understanding of microbial interactions with granular media is important with respect to the removal of microorganisms in water filtration systems. In granular media, the movement of microorganisms is mainly controlled by advective-dispersive transport and attachment to solid matrices [2]. The deposition of microorganisms on granular media is affected by the properties of the granular media (e.g., surface charge and grain size), solution chemistry (e.g., ionic strength, $\mathrm{pH}$ and ionic composition) and characteristics of the microorganisms (e.g., cell surface charge and hydrophobicity) [3, 4].

Point-of-use (POU) water treatment alternatives are of considerable interest as they provide safe drinking water and subsequently prevent water-related diseases. POU treatment could be directly applied to treat the water used at a single tap within a home [5-9]. Layered double hydroxides (LDHs) could be used in POU treatment systems to remove microbial pathogens. LDHs are a class of nanostructured anionic clays, consisting of positively charged brucite-like sheets, which are balanced by the intercalation of anions in the hydrated interlayer regions [10]. Because of their high surface area, large anion exchange capacity, and good thermal stability [11-13], LDHs have been studied for their potential application to microbial removal [14, 15]. Iron (hydr)oxides (IHs) could also be applied to remove microorganisms. Through the modification of the surface charges on granular media with IHs, the microbial removal in water filtration systems could be enhanced [16-18]. Further experiments and quantitative analyses are required to improve our knowledge regarding the microbial removal using these hydroxides.

The objective of this study was to investigate the microbial removal using LDHs and IHs immobilized onto granular media with three sets of column experiments. The first experiments were performed on calcium alginate beads (CA beads) and LDHs entrapped in CA beads (LDH beads), while the second and third experiments were carried out on iron hydroxide-coated sand (IHCS) and hematite-coated sand (HCS). Microbial break-

Received March 21, 2010 Accepted August 12, 2010

(c) This is an Open Access article distributed under the terms of the Creative Commons Attribution Non-Commercial License (http://creativecommons. org/licenses/by-nc/3.0/) which permits unrestricted non-commercial use, distribution, and reproduction in any medium, provided the original work is properly cited.
${ }^{\dagger}$ Corresponding Author

E-mail: songbkim@snu.ac.kr

Tel: +82-2-880-4587 Fax: +82-2-873-2087 
through curves (BTCs) were obtained by monitoring the effluent, with the percentage of microbial removal and the collector efficiency quantified using the curves.

\section{Materials and Methods}

\subsection{Microorganisms}

E. coli ATCC 11105, obtained from the Korea Culture Center for Microorganisms, was used in the experiments. All glassware and materials used in the study were sterilized by autoclaving at $121^{\circ} \mathrm{C}$ and 17.6 psi for 20 minutes to prevent any interference from other microorganisms. Initially, the freeze-dried bacteria were revived in 250-mL Erlenmeyer flasks, containing $100 \mathrm{~mL}$ of $\mathrm{LB}$ medium (tryptone $10 \mathrm{~g}$, yeast extract $5 \mathrm{~g}, \mathrm{NaCl} 5 \mathrm{~g}$ in one liter of deionized water at $\mathrm{pH}$ of 7.0 ), for 84 hours at $30^{\circ} \mathrm{C}$. Then, one milliliter of culture was transferred to $500 \mathrm{~mL}$ of $\mathrm{LB}$ broth, and the bacteria incubated for 84 hours at $30^{\circ} \mathrm{C}$. The suspension was centrifuged at $4^{\circ} \mathrm{C}$ and $10,000 \mathrm{rpm}$ for 15 minutes. The supernatant was removed and replaced with deionized water to prevent growth of the bacteria. The diluted bacteria were re-centrifuged under the same conditions. The centrifuged bacteria were washed three times with deionized water and resuspended in deionized water to an optical density of 0.5 at $600 \mathrm{~nm}$ (OD600).

Transmission electron microscopy (JEM 1010; JEOL, Tokyo, Japan) was used to obtain images of the E. coli cells. The images were imported into an image-processing program (Image-Pro Plus) and analyzed. The average length and diameter of the $E$. coli were 2.2 and $0.6 \mu \mathrm{m}$, respectively, which corresponded to an equivalent spherical diameter of $1.21 \mu \mathrm{m}$. The net surface electrostatic characteristics of the cells were analyzed with an electrophoretic light scattering spectrophotometer (ELS-8000; Otsuka Electronics, Tokyo, Japan). The electrophoretic mobility was determined for the bacterial surface at different $\mathrm{NaCl}$ concentrations (1, 10 and $100 \mathrm{mM}$ ) and converted to zeta potentials using the Smoluchowski equation. About 10 separate readings were conducted, with the average values presented.

\subsection{Granular Media}

All chemicals used for the experiments were purchased from Sigma Aldrich. LDH powders were prepared by co-precipitating mixtures of magnesium nitrate $\left[\mathrm{Mg}\left(\mathrm{NO}_{3}\right)_{2} \cdot 6 \mathrm{H}_{2} \mathrm{O}\right]$ and aluminum nitrate $\left[\mathrm{Al}\left(\mathrm{NO}_{3}\right)_{3} \cdot 9 \mathrm{H}_{2} \mathrm{O}\right]$. A $700 \mathrm{~mL}$ solution $(\mathrm{Mg} / \mathrm{Al}$ molar ratio = 2) of $\mathrm{Mg}\left(\mathrm{NO}_{3}\right)_{2} \cdot 6 \mathrm{H}_{2} \mathrm{O}(1 \mathrm{~mol})$ and $\mathrm{Al}\left(\mathrm{NO}_{3}\right)_{3} \cdot 9 \mathrm{H}_{2} \mathrm{O}(0.5 \mathrm{~mol})$ was added drop wise, using a peristaltic pump (QG400; Fasco, Springfield, MO, USA) at a rate of $3 \mathrm{~mL} / \mathrm{min}$, into $1,000 \mathrm{~mL}$ of an alkali solution $(\mathrm{pH}=13)$ of sodium hydroxide $(\mathrm{NaOH})$ and sodium carbonate $\left(\mathrm{Na}_{2} \mathrm{CO}_{3}\right)$, with intensive stirring, at room temperature. The resulting precipitates were oven-dried at $65^{\circ} \mathrm{C}$ for 18 hours, and then washed thoroughly with deionized water to remove excess sodium, with the final suspensions centrifuged at $8,500 \mathrm{rpm}$ for 20 minutes. The washed precipitates were ovendried again at $65^{\circ} \mathrm{C}$ for 24 hours and then pulverized in a ball mill. The Mg-Al LDHs used for the preparation of the LDH beads were finally obtained via calcination at $573 \mathrm{~K}$ for 24 hours in an electric muffle furnace (C-FMA; Vision Lab, Seoul, Korea).

The LDH beads were prepared by entrapping a powdered form of Mg-Al LDHs in a calcium alginate gel. Two grams of sodium alginate powder were added to $200 \mathrm{~mL}$ of deionized water at room temperature to prepare a sodium alginate solution. The desired amount of LDHs (8\% w/v) was then added to $200 \mathrm{~mL}$ alginate solution, with intensive stirring, to obtain a homogeneous suspension. The suspension, contained in a plastic syringe (outlet diameter $=2 \mathrm{~mm}$ ), was allowed to drop into a stirred reservoir containing $500 \mathrm{~mL}$ of $0.3 \mathrm{M}$ calcium chloride $\left(\mathrm{CaCl}_{2}\right)$ solution in order to form $4.15 \pm 0.23 \mathrm{~mm}(\mathrm{n}=90)$ spherical LDH beads. The beads were allowed to cure in the same $\mathrm{CaCl}_{2}$ solution for 24 hours, with stirring, and then rinsed with deionized water to remove any excess $\mathrm{Ca}^{2+}$.

Quartz sand (QS) was also used in the experiments (Jumunjin Silica, Kangreung, Korea). Mechanical sieving was conducted with US Standard Sieves Nos. 35 and 10. Sand fractions, with a grain size of $0.5-2.0 \mathrm{~mm}$ and a mean diameter of $1.0 \mathrm{~mm}$, were used in the experiments. Before use, the sand was washed twice using deionized water to remove impurities from the surface, with the wet sand autoclaved for 20 minutes at $17.6 \mathrm{psi}$, cooled to room temperature, and then oven-dried at $105^{\circ} \mathrm{C}$ for $1-2$ days. For the preparation of the IHCS, $\mathrm{FeCl}_{3} \cdot 6 \mathrm{H}_{2} \mathrm{O}(5.5 \mathrm{~g})$ was dissolved in deionized water $(100 \mathrm{~mL})$, with the solution $\mathrm{pH}$ adjusted using $6 \mathrm{M} \mathrm{NaOH}$. The QS ( $200 \mathrm{~g}$ ) was added to $\mathrm{FeCl}_{3} \cdot 6 \mathrm{H}_{2} \mathrm{O}$ solution and then mixed in a rotary evaporator $\left(90^{\circ} \mathrm{C}, 80 \mathrm{rpm}, 20 \mathrm{~min}\right.$ utes) to remove the water in the suspension by heating (Hahnvapor; Hahnshin Scientific Co., Seoul, Korea). The coated sand was dried at $150^{\circ} \mathrm{C}$ for 6 hours, washed with deionized water and then dried again under the same conditions. HCS was prepared following the same procedures used for the IHCS. The coated sand was thermally treated at $700^{\circ} \mathrm{C}$ for 24 hours, in an electric muffle furnace (C-FMA; Vision Lab), to obtain HCS.

The powdered forms of the LDHs and IHs (Fig. 1) were characterized using powder X-ray diffractometry (XRD, D5005; Bruker AXS, Berlin, Germany), using $\mathrm{Cu} \mathrm{K} \alpha$ radiation. The granular
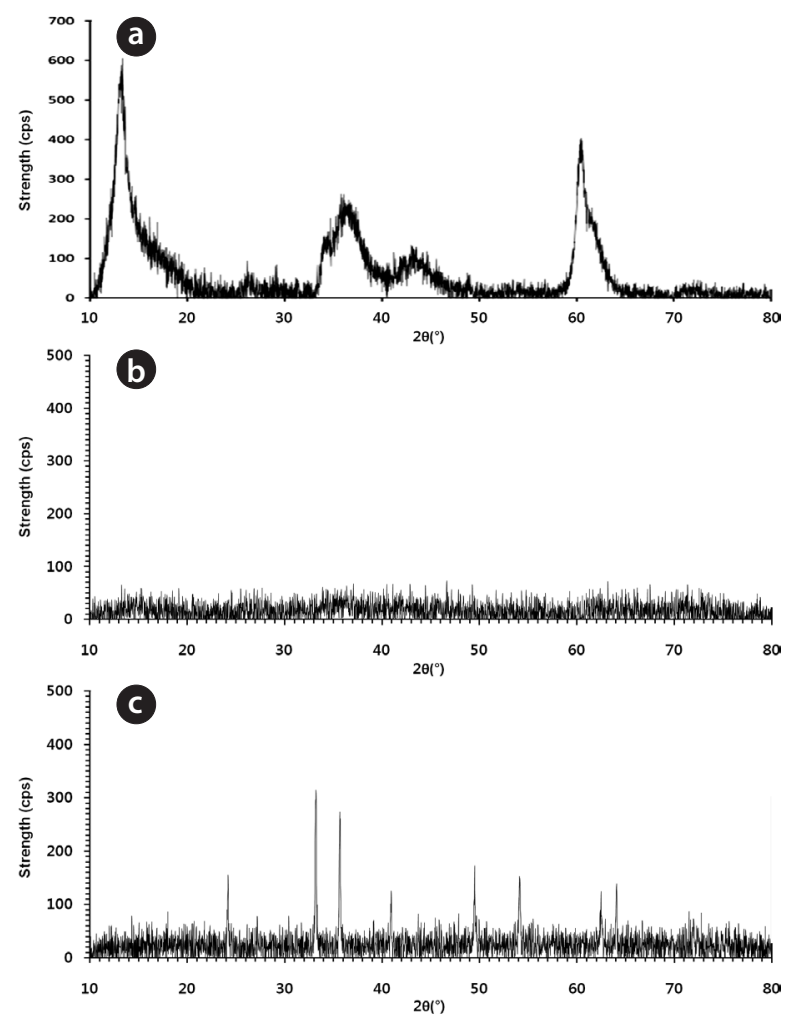

Fig. 1. X-ray diffraction patterns for the powdered forms of: (a) layered double hydroxides, (b) iron hydroxides and (c) hematite. 

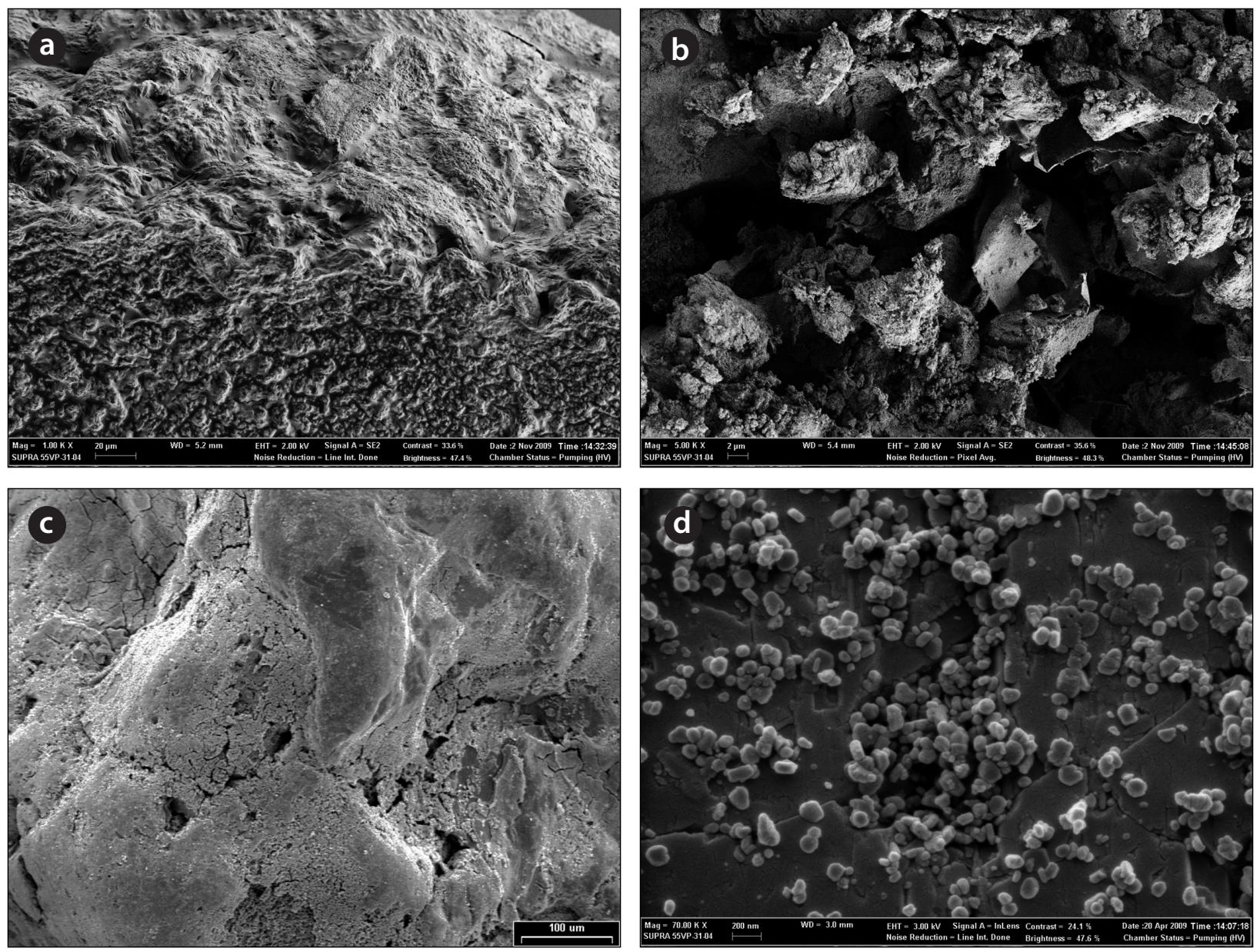

Fig. 2. Field emission scanning electron microscope images: (a) cross-sectional view of a calcium alginate bead (bar $=20 \mu \mathrm{m}$ ), (b) crosssectional view of layered double hydroxides immobilized on a calcium alginate bead (bar $=2 \mu \mathrm{m})$, (c) surface view of iron hydroxide-coated sand $(\mathrm{bar}=100 \mu \mathrm{m})$ and $(\mathrm{d})$ surface view of hematite-coated sand $(\mathrm{bar}=200 \mathrm{~nm})$.

media were observed and examined using X-ray microanalysis (Fig. 2). The granular media were mounted on metal stubs using carbon tape and sputter-coated with platinum (approximately $20 \mathrm{~nm}$ in thickness). Specimens were examined with a field emission scanning electron microscope (FESEM, Supra 55VP; Carl Zeiss, Oberkochen, Germany), at an accelerating voltage of $3 \mathrm{kV}$.

\subsection{Column Experiments}

Column experiments were conducted using Plexiglas columns, with an inner diameter of $2.5 \mathrm{~cm}$ and a height of $10 \mathrm{~cm}$, packed with the granular media. All the experiments were performed in duplicate (Table 1). The column was connected to a HPLC pump (Series II; Scientific Systems, Inc., Woburn, MA, USA), operating at a rate of $0.3 \mathrm{~mL} / \mathrm{min}$. Before the microbial injection, the packed column was flushed upward with 15-20 pore volumes of $\mathrm{NaCl}$ solution $(1,10$ and $100 \mathrm{mM})$ to achieve steady state flow conditions. E. coli (0.5 OD600) were introduced downward into the column for 35 minutes, along with $\mathrm{NaCl}$ solution. After completing the microbial injection, further $\mathrm{NaCl}$ solution was introduced into the column. Effluent samples were collected at regular intervals using an auto collector (Retriever 500; Teledyne Technologies, Inc., Thousand Oaks, CA, USA). Effluents were analyzed for their bacterial concentrations. The microbial concentration was determined by measuring the optical density of the effluent using a UV-visible spectrophotometer (Helios; Thermo Scientific, Waltham, MA, USA) at $600 \mathrm{~nm}$ (OD600). The pH and electrical conductivity (EC) of the influent and effluent solutions were measured with a $\mathrm{pH}$ probe $(9107 \mathrm{BN}$; Orion, Cupertino, CA, USA) and an EC probe (815PDL; Istek, Seoul, Korea), respectively.

\subsection{Data Analysis}

Assuming negligible microbial growth and decay, the onedimensional microbial transport can be described as:

$$
\frac{\partial C}{\partial t}=D \frac{\partial^{2} C}{\partial x^{2}}-v \frac{\partial C}{\partial x}-\lambda C
$$

where $C$ is the microbial concentration in the aqueous phase, $D$ the hydrodynamic dispersion coefficient for microbes, $v$ the velocity for microbes and $\lambda$ the attachment (removal) rate coefficient $(1 / \mathrm{T})$. The parameters in the transport models were ob- 
Table 1. Column experimental conditions, and the results for Escherichia coli in the granular media

\begin{tabular}{|c|c|c|c|c|c|c|c|c|}
\hline Ex. & Media & Solution (mM) & $\nu(\mathrm{cm} / \mathrm{min})$ & $D\left(\mathrm{~cm}^{2} / \mathrm{min}\right)$ & $\lambda(1 / \mathrm{min})$ & $R^{2}$ & $R(\%)$ & $C e$ \\
\hline $1 \mathrm{a}$ & CA beads & 1 & 0.172 & 0.239 & 0.0084 & 0.99 & 40.0 & 0.0177 \\
\hline $1 b$ & CA beads & 1 & 0.171 & 0.309 & 0.0090 & 0.98 & 41.6 & 0.0186 \\
\hline $2 a$ & CA beads & 10 & 0.167 & 0.149 & 0.0036 & 0.98 & 17.4 & 0.0066 \\
\hline $2 b$ & CA beads & 10 & 0.169 & 0.144 & 0.0045 & 0.99 & 23.5 & 0.0083 \\
\hline $3 a$ & LDH beads & 1 & 0.167 & 0.101 & 0.0051 & 0.98 & 26.1 & 0.0092 \\
\hline $3 b$ & LDH beads & 1 & 0.168 & 0.195 & 0.0055 & 0.99 & 29.2 & 0.0105 \\
\hline $4 a$ & LDH beads & 10 & 0.161 & 0.083 & 0.0016 & 0.99 & 3.7 & 0.0011 \\
\hline $4 \mathrm{~b}$ & LDH beads & 10 & 0.162 & 0.096 & 0.0017 & 0.98 & 4.1 & 0.0013 \\
\hline $5 a$ & QS & 1 & 0.150 & 0.048 & 0.0086 & 0.99 & 23.5 & 0.0030 \\
\hline $5 b$ & QS & 1 & 0.148 & 0.069 & 0.0089 & 1.00 & 26.9 & 0.0034 \\
\hline $6 a$ & IHCS & 1 & 0.156 & 0.054 & 0.0316 & 0.96 & 85.7 & 0.0218 \\
\hline $7 \mathrm{a}$ & IHCS & 10 & 0.156 & 0.054 & 0.0333 & 0.99 & 87.2 & 0.0228 \\
\hline $7 \mathrm{~b}$ & IHCS & 10 & 0.157 & 0.057 & 0.0326 & 1.00 & 86.3 & 0.0227 \\
\hline $8 \mathrm{a}$ & IHCS & 100 & 0.157 & 0.033 & 0.0317 & 0.99 & 86.1 & 0.0222 \\
\hline $8 b$ & IHCS & 100 & 0.148 & 0.089 & 0.0312 & 0.99 & 86.3 & 0.0223 \\
\hline $9 a$ & HCS & 1 & 0.151 & 0.075 & 0.0056 & 1.00 & 34.1 & 0.0045 \\
\hline $9 b$ & HCS & 1 & 0.150 & 0.128 & 0.0068 & 1.00 & 37.0 & 0.0050 \\
\hline $10 \mathrm{a}$ & HCS & 10 & 0.150 & 0.045 & 0.0098 & 1.00 & 47.4 & 0.0071 \\
\hline $10 \mathrm{~b}$ & HCS & 10 & 0.151 & 0.050 & 0.0106 & 1.00 & 50.5 & 0.0078 \\
\hline $11 \mathrm{a}$ & HCS & 100 & 0.150 & 0.048 & 0.0122 & 1.00 & 54.5 & 0.0087 \\
\hline $11 \mathrm{~b}$ & HCS & 100 & 0.151 & 0.050 & 0.0118 & 0.99 & 52.2 & 0.0083 \\
\hline
\end{tabular}

CA beads: calcium alginate beads, LDH beads: layered double hydroxides immobilized on calcium alginate beads, QS: quartz sand, IHCS: iron hydroxide-coated sand, HCS: hematite-coated sand.

tained by fitting the CXTFIT code [19] to the breakthrough data. The percentage of microbial removal $(R)$ in the effluent was quantified by the following equation:

$$
R=\left(1-\frac{\int_{0}^{\infty} C d t}{C_{0} t_{0}}\right) \times 100 \quad(\%)
$$

where $C_{0}$ is the initial concentration of microbes and $t_{0}$ the duration of microbial injection (injection time).

From colloid filtration theory, the removal of biocolloids/ colloids from suspension by attachment to a collector can be described by the collector efficiency $(C e)$, which denotes the probability that a colloidal particle approaching a collector both collides with and sticks to the collector [20]:

$$
C e=\eta \alpha
$$

where $\eta$ is the collision efficiency, which is the probability that a colloidal particle approaching a collector collides with the collector, and $\alpha$ the sticking efficiency, which is the probability that the particle colliding with the collector sticks to that collector. The collision efficiency is calculated using the following Eq. [21]:

$$
\eta=2.4 A_{S}^{1 / 3} N_{R}^{-0.081} N_{P_{e}}^{-0.715} N_{v d W}^{0.052}+0.55 A_{S} N_{R}^{1.675} N_{A}^{0.125}+0.22 N_{R}^{-0.24} N_{G}^{1.11} N_{v d W}^{0.053}
$$

where $A_{S}$ is the porosity-dependent parameter, $N_{R}$ the aspect ratio, $N_{P e}$ the Peclet number, $N_{v d W}$ the van der Waals number, $N_{A}$ the attraction number and $N_{G}$ the gravity number. The sticking efficiency is determined using the following Eq. [21]:

$$
\alpha=-\frac{2}{3} \frac{d_{c}}{(1-n) L \eta} \ln \left(1-\frac{R}{100}\right)
$$

where $d c$ is the particle diameter of collector grain, $L$ the column length and $n$ the porosity. The parameters used in the calculation of the collector efficiency are summarized in Table 2.

Table 2. Parameters used in the calculation of the collector efficiency ( $C e$ ) for Escherichia coli in the granular media

\begin{tabular}{lcc}
\hline Parameter & Unit & Value \\
\hline Column length & $\mathrm{cm}$ & 10 \\
Particle diameter of collector grain (sand, beads) & $\mathrm{mm}$ & $1.0,4.15$ \\
Particle diameter of colloidal particle (bacteria) & $\mu \mathrm{m}$ & 1.21 \\
Particle density of colloidal particle (bacteria) $^{\mathrm{a}}$ & $\mathrm{g} / \mathrm{cm}^{3}$ & 1.105 \\
Fluid absolute temperature & $\mathrm{K}$ & 298 \\
Fluid density & $\mathrm{g} / \mathrm{cm}^{3}$ & 0.997 \\
Fluid viscosity & $\mathrm{g} / \mathrm{cm} / \mathrm{s}$ & $8.91 \times 10^{-3}$ \\
Hamaker constant & $\mathrm{J}$ & $6.5 \times 10^{-21}$ \\
Boltzmann constant & $\mathrm{J} / \mathrm{K}$ & $1.38 \times 10^{-23}$ \\
Bulk diffusion coefficient & $\mathrm{cm}^{2} / \mathrm{sec}$ & $4.05 \times 10^{-9}$ \\
\hline
\end{tabular}

${ }^{a}$ Particle density of bacteria was from Martinez-Salas et al. [22]. 


\section{Results and Discussion}

\subsection{Microbial BTCs}

The microbial BTCs obtained from the column experiments using the granular media are presented in Fig. 3 . With the CA beads and LDH beads (Fig. 3a), the BTCs had well defined single peaks, with different relative peak concentrations depending on the granular medium and ionic strength. The relative peak concentrations ranged from 0.323 to 0.601 , with the lowest obtained for $1 \mathrm{mM}$ solution and alginate beads (Ex. 1), and the highest with $10 \mathrm{mM}$ solution and LDH beads (Ex. 4). The transport pa-
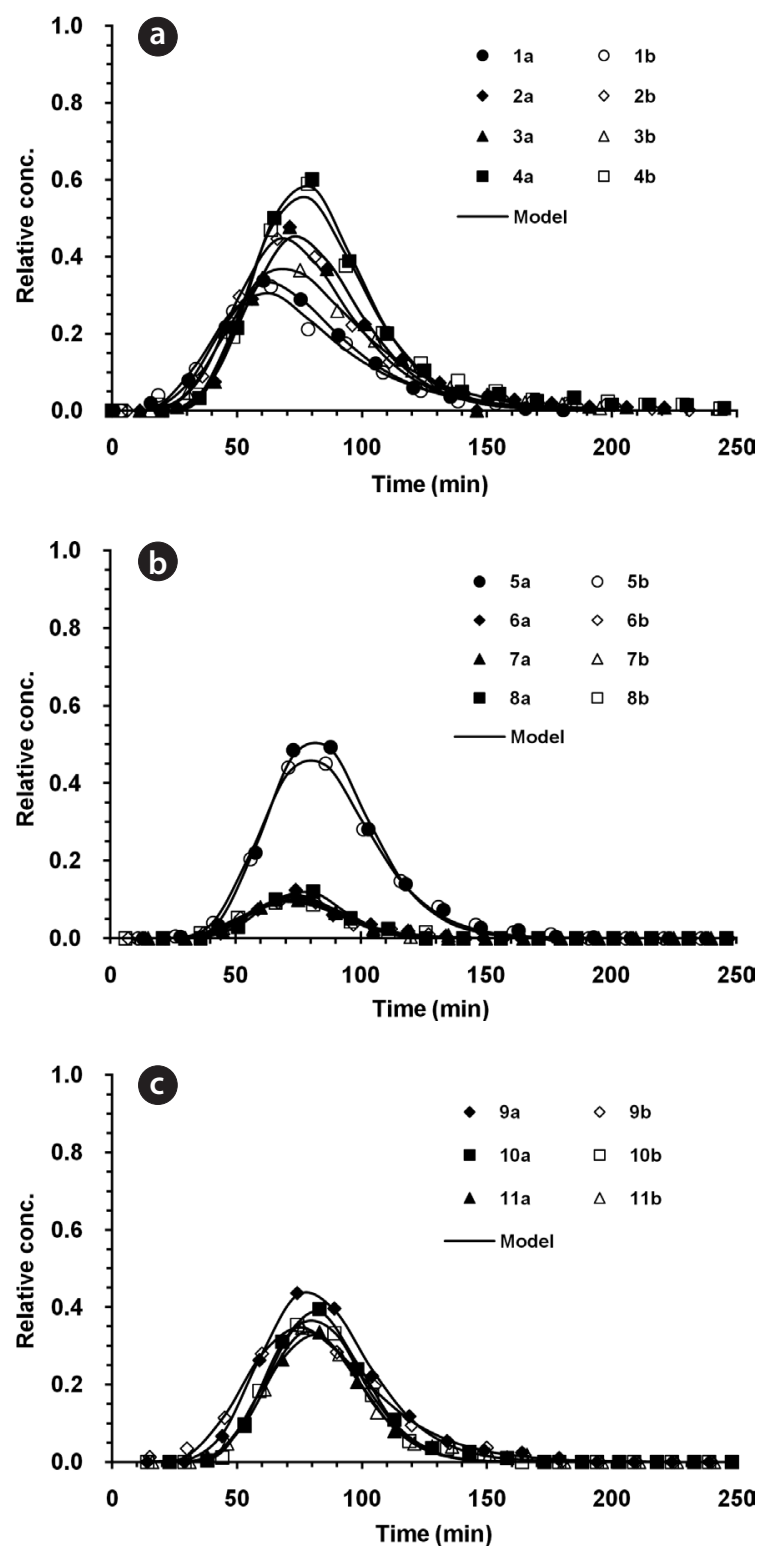

Fig. 3. Breakthrough curves of Escherichia coli obtained from column experiments: (a) calcium alginate beads and layered double hydroxides immobilized on calcium alginate beads (Ex. 1a-4b), (b) quartz sand and iron hydroxide-coated sand (Ex. 5a-8b) and (c) hematite-coated sand (Ex. 9a-11b). rameters $(\nu$ and $D)$ obtained from the model fit for the microbial BTCs were $0.167 \pm 0.003 \mathrm{~cm} / \mathrm{min}$ and $0.165 \pm 0.074 \mathrm{~cm}^{2} / \mathrm{min}$, respectively. The attachment rate coefficients $(\lambda)$ ranged from 0.0016 to $0.00901 / \mathrm{min}$, with the lowest with $10 \mathrm{mM}$ solution and LDH beads (Ex. 4), and the highest for $1 \mathrm{mM}$ solution and CA beads (Ex. 1) (Table 1).

The microbial BTCs from the experiments with QS and IHCS are given in Fig. 3b. The BTCs also had well-defined single peaks, with the relative peak concentrations ranging from 0.092 to 0.493 , with the highest obtained for $1 \mathrm{mM}$ quartz sand (Ex. 5). The values of $v$ and $D$ determined from the BTCs were $0.153 \pm$ $0.004 \mathrm{~cm} / \mathrm{min}$ and $0.061 \pm 0.017 \mathrm{~cm}^{2} / \mathrm{min}$, respectively. The values of $\lambda$ was $0.0088 \pm 0.0002$ and $0.0319 \pm 0.00091 / \mathrm{min}$ with QS and IHCS, respectively, which remained constant, even though the ionic strength of the leaching solution increased. With the HCS (Fig. 3c), the BTCs had relative peak concentrations ranging from 0.335 to 0.437 , with the highest for $1 \mathrm{mM}$ solution (Ex. 9) and the lowest for $100 \mathrm{mM}$ solution (Ex. 11). The values of $v$ and $D$ were $0.151 \pm 0.001 \mathrm{~cm} / \mathrm{min}$ and $0.066 \pm 0.029 \mathrm{~cm}^{2} / \mathrm{min}$, respectively. The values of $\lambda$ ranged from 0.0056 to $0.01221 / \mathrm{min}$, increasing with increasing ionic strength of solution (Table 1).

\subsection{Microbial Removal Percent and Collector Efficiency}

The percentage microbial removal and collector efficiency with $1 \mathrm{mM}$ solution for the granular media are presented in Fig. 4. As shown in Fig. 4a, the average percentage removal $(R)$ was highest for IHCS and lowest for QS. With the CA beads, the average percentage removal was $40.8 \%(1 \mathrm{a}=40.0,1 \mathrm{~b}=41.6)$, but $27.7 \%$ with the LDH beads ( $3 a=26.1,3 b=29.2$ ). The average percentage removal for QS was $25.2 \%(5 a=23.5,5 b=26.9)$, which was lower than those for CA beads and LDH beads. With the IHCS, the average percentage removal was $86.0 \%(6 \mathrm{a}=85.7$, $6 \mathrm{~b}=86.2$ ), which was about 3.4 times higher than that for QS. The average percentage removal with HCS was $35.6 \%(9 \mathrm{a}=34.1$, $9 b=37.0)$.
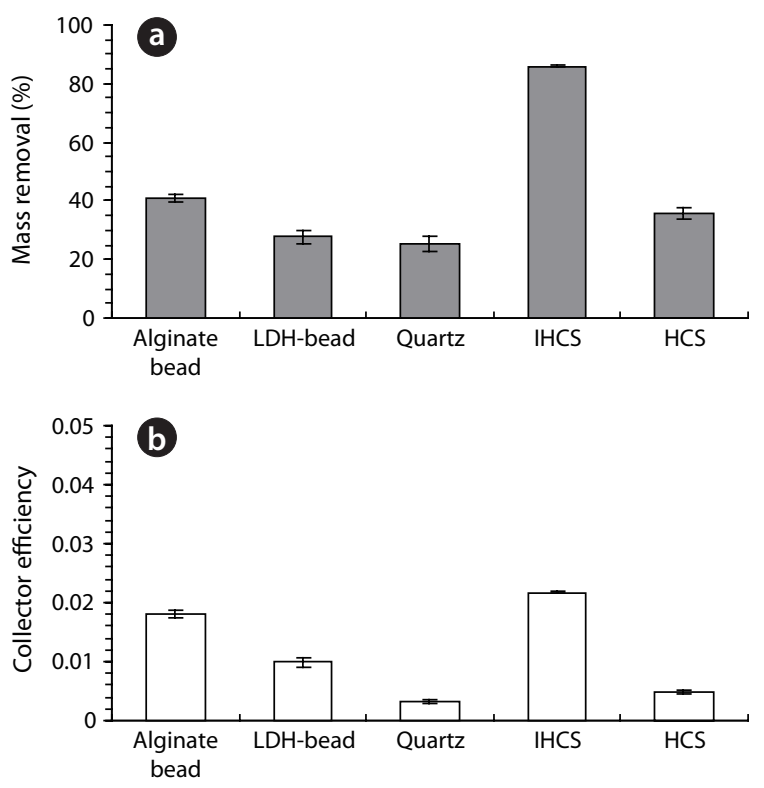

Fig. 4. Percentage microbial removal (a) and collector efficiency (b) of the granular media ( $1 \mathrm{mM}$ solution). 

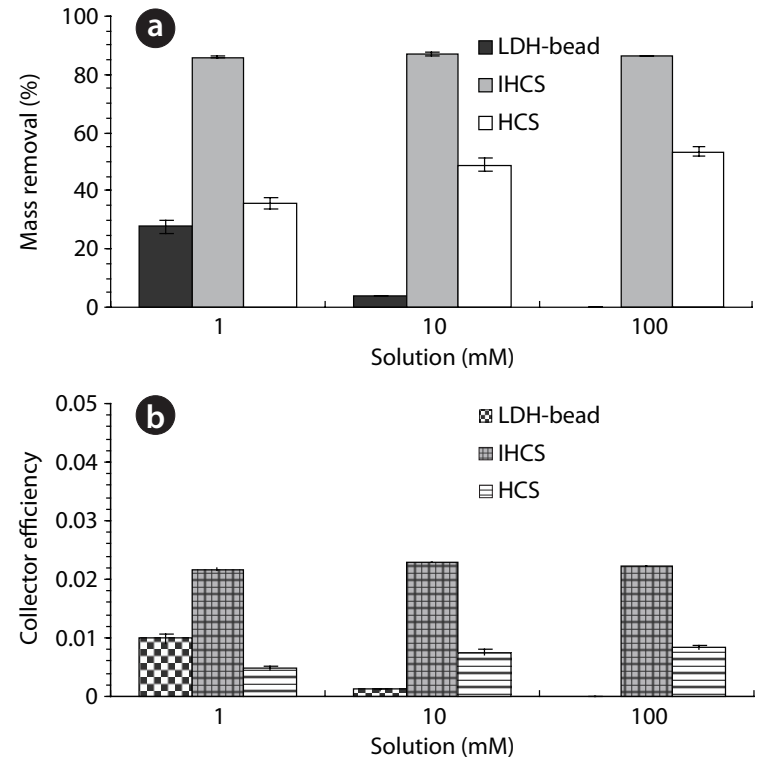

Fig. 5. Percentage microbial removal (a) and collector efficiency (b) of the granular media under different ionic strengths.

As presented in Fig. 4b, the average collector efficiency $(\mathrm{Ce})$ was lowest with QS and highest with IHCS. With the CA beads, the average collector efficiency was $0.0181(1 \mathrm{a}=0.0177,1 \mathrm{~b}=$ $0.0186)$, which was about two times higher than that $(=0.0099)$ of the LDH beads $(3 \mathrm{a}=0.0092,3 \mathrm{~b}=0.0105)$. The average collector efficiency for QS was $0.0032(5 a=0.0030,5 b=0.0034)$. With the IHCS, the average collector efficiency was $0.0218(6 \mathrm{a}=$ $0.0218,6 b=0.0217$ ), which was one order of magnitude higher than that of the QS. The average collector efficiency with HCS was $0.0048(9 \mathrm{a}=0.0045,9 \mathrm{~b}=0.0050)$.

The percentage microbial removal and collector efficiency with the various solutions (1, 10 and $100 \mathrm{mM}$ ) are presented in Fig. 5. As shown in Fig. 5a, the average percentage removal with the LDH beads decreased from 27.7 to $3.9 \%$ ( $4 \mathrm{a}=3.7,4 \mathrm{~b}$ $=4.1$ ) on increasing the ionic strength from 1 to $10 \mathrm{mM}$. Note: no column result was obtained for LDH beads in $100 \mathrm{mM}$ solution due to unstable behavior of the $\mathrm{LDH}$ beads. When $\mathrm{NaCl}$ was added to adjust the ionic strength, the $\mathrm{Na}^{+}$ions partially displace $\mathrm{Ca}^{2+}$ ions from the alginate hydrogel beads [23]. With the IHCS, the average percentage removal remained constant at around $86.0 \%$, even though the ionic strength was increased from 1 to $100 \mathrm{mM}$. Meanwhile, the average percentage removal with the HCS gradually increased from 35.6 to $53.4 \%(11 \mathrm{a}=54.5,11 \mathrm{~b}=$ 52.2) with increasing ionic strength from 1 to $100 \mathrm{mM}$ (Table 1).

As shown in Fig. 5b, the average collector efficiency $(\mathrm{Ce})$ for the LDH beads decreased from 0.0099 to 0.0012 ( $4 \mathrm{a}=0.0011,4 \mathrm{~b}$ $=0.0013$ ) with increasing ionic strength from 1 to $10 \mathrm{mM}$. With the IHCS, the average collector efficiency remained constant at around 0.0222 , even though the ionic strength was increased from 1 to $100 \mathrm{mM}$. The average collector efficiency for HCS increased from 0.0048 to $0.0085(11 \mathrm{a}=0.0087,11 \mathrm{~b}=0.0083)$ with increasing ionic strength from 1 to $100 \mathrm{mM}$ (Table 1).

\subsection{Microbial Removal in Granular Media}

Sodium alginate, a water-soluble salt of alginic acid, is an anionic linear polysaccharide composed of repeated (1-4)-linked
D-mannuronic and L-glucuronic acid units. Calcium ions can chelate carboxylate groups, make crosslinks between chains, and form an insoluble hydrogel [24]. CA beads are an anionic biopolymer, with a point of zero charge $\left(\mathrm{pH}_{\mathrm{pzc}}\right)$ of 6.5 [25]. The $\mathrm{pH}_{\mathrm{pzc}}$ is the $\mathrm{pH}$ where the net surface charge is equal to zero. The surface charge of CA beads depends on the solution $\mathrm{pH}$. Therefore, CA beads carry a positive charge below the $\mathrm{pH}_{\mathrm{pzc}}$, but a negative charge above that. In our experiments with CA beads in $1 \mathrm{mM}$ solution (Ex. 1a and b), where the solution $\mathrm{pH}$ was around 7.2 , the surface of the CA beads would have been negatively charged, such that the electrostatic interaction between the CA beads and E. coli would be repulsive. Note: $E$. coli is negatively charged in $1 \mathrm{mM}$ solution (zeta potential $=-34.2 \mathrm{mV}$ ); that is, the adhesion of E. coli to the surface of CA beads would be unfavorable in terms of their electrostatic interaction. The average percentage removal with CA beads in $1 \mathrm{mM}$ solution was $40.8 \%$ (Fig. 4). This removal (adhesion) could be attributed to the polymeric interaction between the polysaccharides of the CA beads and E. coli. Polysaccharides, such as lipopolysaccharides (LPS), and exopolymeric substances (EPS) on bacterial cell surfaces might play major roles in the bacterial adhesion to the surface of CA beads (polysaccharide) via polymeric interaction [26, 27].

LDHs have $\mathrm{pH}_{\mathrm{pzc}}$ of between 10 and 11 [15]; therefore, they would have been positively charged under our experimental conditions (solution $\mathrm{pH}=8.3$ ). The negatively charged $E$. coli might be effectively attached to the LDHs via electrostatic interaction. In our experiments; however, the LDH beads were not effective for microbial removal (27.7\% at $1 \mathrm{mM}$ solution) (Fig. 4). This could have been related with how the LDHs were immobilized in the CA beads during the synthesis stage (Fig. 2b). LDH powders were immobilized inside the CA beads, with pore sizes of about $10 \mathrm{~nm}$ [28]. Therefore, E. coli (equivalent diameter $=1.21 \mu \mathrm{m}$ ) could not diffuse through the pores to come into contact with the LDHs located on the interior of the CA beads, but could only adhere to the exterior surface of the CA beads.

Of the granular media used in our experiments, IHCS was most effective ( $86.0 \%$ in $1 \mathrm{mM}$ solution) at microbial removal (Fig. 4). This could be attributed to the iron hydroxide $\left(\mathrm{Fe}(\mathrm{OH})_{3}\right)$ coated on the exterior surface of QS having a positive surface charge (zeta potential $=9.7 \mathrm{mV}$ ), which effectively attracted the negatively-charged microbes. Note: the iron hydroxide was poorly crystallized, as indicated by the XRD data (Fig. 1b). Meanwhile, HCS was far less effective ( $35.6 \%$ in $1 \mathrm{mM}$ solution) at microbial removal than IHCS (Fig. 4). This could be ascribed to the hematite $\left(\mathrm{Fe}_{2} \mathrm{O}_{3}\right)$ coated on the external surface of QS being a crystallized iron oxide (Fig. 1c) with a negative surface charge (zeta potential $=-1.8 \mathrm{mV}$ ).

The average percentage removals in $1 \mathrm{mM}$ solution for both CA beads and LDH beads were higher than those in $10 \mathrm{mM}$ solution (Fig. 5). This could be ascribed to the bacterial polysaccharides being fully extended from the cell surface at low ionic strengths, resulting in increased bacterial adhesion to the surfaces [29]. With the IHCS, the percentage removal remained constant on increasing the ionic strength from 1 to $100 \mathrm{mM}$ (Fig. 5). This might be attributable to E. coli having many carboxyl (COOH) groups on its outer membrane [30] and; thus, could be adsorbed to IHCS via an inner-sphere complex, with minimal impact due to the ionic strength [31]. With the HCS, the percentage removal increased with increasing ionic strength (Fig. 5). This could be explained by the Derjaguin-Landau-VerweyOverbeek (DLVO) theory [32], because both HCS and bacteria are negatively-charged. An increase in the ionic strength could 
lead to a decrease in the thickness of the electrical double layers and in the average distance between the HCS and bacteria, subsequently resulting in the promotion of bacterial removal with HCS

\section{Conclusions}

The microbial removals using LDHs and IHs immobilized on granular media were investigated using column experiments. The results showed that LDH beads were not effective for the removal of negatively-charged microbes, even though the positively-charged LDHs were contained in the beads. This could be related to the immobilization method, where LDH powders were immobilized inside the CA beads, with nano-sized pores; therefore, micro-sized microbes could not diffuse through the pores to come into contact with the LDHs in the bead, but would only adhere to the exterior surface of the bead via polymeric interaction. IHCS was most effective for the microbial removal, which could be attributed to the iron hydroxide coated on the exterior surface of the QS having a positive surface charge; therefore, would be effectively attracted to the negatively-charged microbes via electrostatic interaction. Meanwhile, HCS was far less effective than IHCS because the hematite coated on the external surface of QS is a crystallized iron oxide with a negative surface charge. This study has helped improve our knowledge on the potential application of functional granular media for microbial removal.

\section{Acknowledgments}

This research was supported by the National Research Foundation of Korea, funded by the Ministry of Education, Science and Technology, Korea (grant number 2009-0073524).

\section{References}

1. Souter PF, Cruickshank GD, Tankerville MZ, et al. Evaluation of a new water treatment for point-of-use household applications to remove microorganisms and arsenic from drinking water. J. Water Health 2003;1:73-84.

2. Hornberger GM, Mills AL, Herman JS. Bacterial transport in porous media: Evaluation of a model using laboratory observations. Water Resour. Res. 1992;28:915-923.

3. Gannon JT, Manilal VB, Alexander M. Relationship between cell surface properties and transport of bacteria through soil. Appl. Environ. Microbiol. 1991;57:190-193.

4. Fontes DE, Mills AL, Hornberger GM, Herman JS. Physical and chemical factors influencing transport of microorganisms through porous media. Appl. Environ. Microbiol. 1991;57:2473-2481.

5. Lantagne DS, Blount BC, Cardinali F, Quick R. Disinfection by-product formation and mitigation strategies in point-ofuse chlorination of turbid and non-turbid waters in Western Kenya. J. Water Health 2008;6:67-82.

6. Brownell SA, Chakrabarti AR, Kaser FM, et al. Assessment of a low-cost, point-of-use, ultraviolet water disinfection technology. J. Water Health 2008;6:53-65.

7. Doocy S, Burnham G. Point-of-use water treatment and diarrhoea reduction in the emergency context: An effectiveness trial in Liberia. Trop. Med. Int. Health 2006;11:1542-1552.

8. Gurian PL, Small MJ. Point-of-use treatment and the revised arsenic MCL. J. Am. Water Works Assoc. 2002;94:101-108.

9. Slotnick MJ, Meliker JR, Nriagu JO. Effects of time and pointof-use devices on arsenic levels in Southeastern Michigan drinking water, USA. Sci. Total Environ. 2006;369:42-50.

10. Goh KH, Lim TT, Dong Z. Application of layered double hydroxides for removal of oxyanions: a review. Water Res. 2008;42:1343-1368.

11. Cavani F, Trifiro F, Vaccari A. Hydrotalcite-type anionic clays: Preparation, properties and applications. Catal. Today 1991;11:173-301.

12. Vaccari A. Preparation and catalytic properties of cationic and anionic clays. Catal. Today 1998;41:53-71.

13. Das NN, Konar J, Mohanta MK, Srivastava SC. Adsorption of $\mathrm{Cr}(\mathrm{VI})$ and $\mathrm{Se}(\mathrm{IV})$ from their aqueous solutions onto $\mathrm{Zr} 4+-$ substituted $\mathrm{ZnAl} / \mathrm{MgAl}$-layered double hydroxides: Effect of $\mathrm{Zr} 4+$ substitution in the layer. J. Colloid Interface Sci. 2004;270:1-8.

14. Jin S, Fallgren PH, Morris JM, Chen Q. Removal of bacteria and viruses from waters using layered double hydroxide nanocomposites. Sci. Tech. Adv. Mater. 2007;8:67-70.

15. You Y, Vance GF, Sparks DL, Zhuang J, Jin Y. Sorption of MS2 bacteriophage to layered double hydroxides: effects of reaction time, pH, and competing anions. J. Environ. Qual. 2003;32:2046-2053.

16. Foppen JW, Liem Y, Schijven J. Effect of humic acid on the attachment of Escherichia coli in columns of goethite-coated sand. Water Res. 2008;42:211-219.

17. Lukasik J, Cheng YF, Lu F, Tamplin M, Farrah SR. Removal of microorganisms from water by columns containing sand coated with ferric and aluminum hydroxides. Water Res. 1999;33:769-777.

18. Kim SB, Park SJ, Lee CG, Choi NC, Kim DJ. Bacteria transport through goethite-coated sand: Effects of solution $\mathrm{pH}$ and coated sand content. Colloids Surf. B. Biointerfaces 2008;63:236-242.

19. Toride N, Leij FJ, Van Genuchten MT. The CXTFIT code for estimating transport parameters from laboratory or field tracer experiments. Riverside, CA: U.S. Salinity Laboratory. 1995. Research Report No. 137.

20. Cail TL, Hochella Jr MF. The effects of solution chemistry on the sticking efficiencies of viable Enterococcus faecalis: An atomic force microscopy and modeling study. Geochim. Cosmochim. Acta 2005;69:2959-2969.

21. Tufenkji N, Elimelech M. Correlation equation for predicting single-collector efficiency in physicochemical filtration in saturated porous media. Environ. Sci. Technol. 2004;38:529536.

22. Martinez-Salas E, Martin JA, Vicente M. Relationship of Escherichia coli density to growth rate and cell age. J. Bacteriol. 1981;147:97-100.

23. Velings NM, Mestdagh MM. Physico-chemical properties of alginate gel beads. Polym. Gels Networks 1995;3:311-330.

24. Banerjee A, Nayak D, Lahiri S. A new method of synthesis of iron doped calcium alginate beads and determination of iron content by radiometric method. Biochem. Eng. J. 2007;33:260-262.

25. Escudero C, Fiol N, Villaescusa I, Bollinger JC. Arsenic removal by a waste metal (hydr)oxide entrapped into calcium alginate beads. J. Hazard. Mater. 2009;164:533-541.

26. Tsuneda S, Aikawa H, Hayashi H, Yuasa A, Hirata A. Extracel- 
lular polymeric substances responsible for bacterial adhesion onto solid surface. FEMS Microbiol. Lett. 2003;223:287292.

27. Hori K, Matsumoto S. Bacterial adhesion: From mechanism to control. Biochem. Eng. J. 2010;48:424-434.

28. Klein J, Stock J, Vorlop KD. Pore size and properties of spherical Ca-alginate biocatalysts. Eur. J. Appl. Microbiol. Biotechnol. 1983;18:86-91.

29. Abu-Lail NI, Camesano TA. Elasticity of pseudomonas putida KT2442 surface polymers probed with single-molecule force microscopy. Langmuir 2002;18:4071-4081.

30. Katowsky M, Sabisch A, Gutberlet T, Bradaczek H. Molecular modelling of bacterial deep rough mutant lipopolysaccharide of Escherichia coli. Eur. J. Biochem. 1991;197:707-716.

31. Cornell RM, Schwertmann U. The iron oxides: structure, properties, reactions, occurrence, and uses. New York, NY: VCH; 1996.

32. Poortinga AT, Bos R, Norde W, Busscher HJ. Electric double layer interactions in bacterial adhesion to surfaces. Surf. Sci. Rep. 2002;47:1-32. 